\title{
Public health handling of 'Patient 31 of Seoul' in Northern Province,
} Sri Lanka

\author{
R Kesavan $^{1 *}$, R Surenthirakumaran ${ }^{2}$, PA Dinesh Coonghe ${ }^{2}$, A Ketheeswaran ${ }^{1}$ \\ ${ }^{1}$ Office of the Provincial Director of Health Services, Northern Province, Sri Lanka; ${ }^{2}$ Department of Community \\ and Family Medicine, Faculty of Medicine, University of Jaffna
}

"Correspondence: dr_kesavan@yahoo.com

https://orcid.org/0000-0002-0596-2618

DOI: https://doi.org/10.4038/jccpsl.v26i5.8322

Received on 9 May 2020

Accepted on 9 June 2020

\begin{abstract}
Summary
Northern Province of Sri Lanka was non-exempt from COVID-19 pandemic in Sri Lanka. Through the wellestablished public health system (1-2), stringent measures were initiated with the national leadership and guidance, based on the longstanding experience of natural and man-made disasters. The successful response of a country to COVID-19 depends on how well the strategies are adopted at the sub-national level. Thus, sharing the sub-national successes and challenges faced in handling the first wave of the pandemic would be useful for future response and also as evidence to be considered in a model for enabling public health action. This narrative report describes the steps which have been taken to prevent the spread of COVID-19 in Northern Province, Sri Lanka.
\end{abstract}

\section{Public health response and its impact}

Not knowing its exact nature has been a major bottleneck in controlling the disease in the world (34). The overarching goal of all countries has been to slow down the transmission and reduce mortality and morbidity to a level of low level/ no transmission. Nevertheless, countries need to adopt different strategies to contain the situation based on their resources, health system and their previous experiences (3).

Sri Lanka has proven many achievements in controlling communicable diseases by using public health measures such as identification, testing, isolation (and care for all cases), tracing and quarantine of all contacts, public health and social measures at individual and community level (1-2). The prevention of coronavirus does not differ from that of other viruses, such as SARS and MERS, which have been prevalent in the past. However, the cohesive functioning of national and sub-national level activities along with implementation of contextually and culturally accepted public health and social measures have been the essential elements for containing the COVID-19 pandemic (6). In this regard, the country relied on the strength of the existing public health system and other supportive services. 


\section{Moving ahead of the virus in Northern Province}

In the Northern Province, several measures were taken to prevent the spread of COVID-19. As the first step, the health sector organized the first intersectoral meeting to sensitize and plan for the control measures, along with the departments of Education, Local Government, Police and the Tri-forces. This meeting was held when the first COVID-19 case was reported in Colombo, Sri Lanka on 27 January 2020. Following this, an action plan was contrived.

\section{- Surveillance of the foreign returnees}

The surveillance of foreign returnees who were in self-isolation was the first step done effectively in Northern Province with the guidance and support of the government.

\section{- Control measures at Katchchatheevu festival}

The annual Katchchatheevu festival which is usually held on 7 March 2020 in an island halfway between India and Sri Lanka, where thousands of Indians and Sri Lankans are allowed to attend the festival without formal visa process. This ceremony was expected to be a potential threat for COVID-19 spread in Sri Lanka. As such, intensive measures were taken by the health sector, local government and Tri-forces to prevent any possibility of COVID-19 spread as by then, there was a patient already identified in Kerala, South India. Screening the pilgrims and following-up the suspected individuals were the major medical steps carried out. Details of the pilgrims and residential addresses were recorded to make the tracking easy. There were also arrangements to transfer suspected COVID-19 patients for quarantine. This process not only prevented any transmission but also proved to be a rehearsal for the future battle against COVID-19.

\section{- Quarantine measures in the Palaly International Airport, Jaffna}

A mechanism was put in place with the help of the Tri-forces to screen all the incoming passengers and follow-up on their status, including the transport of suspected COVID-19 persons to the designated COVID-19 ward in the Teaching Hospital Jaffna. Effective micromanagement was the key to dwindle the outspread.

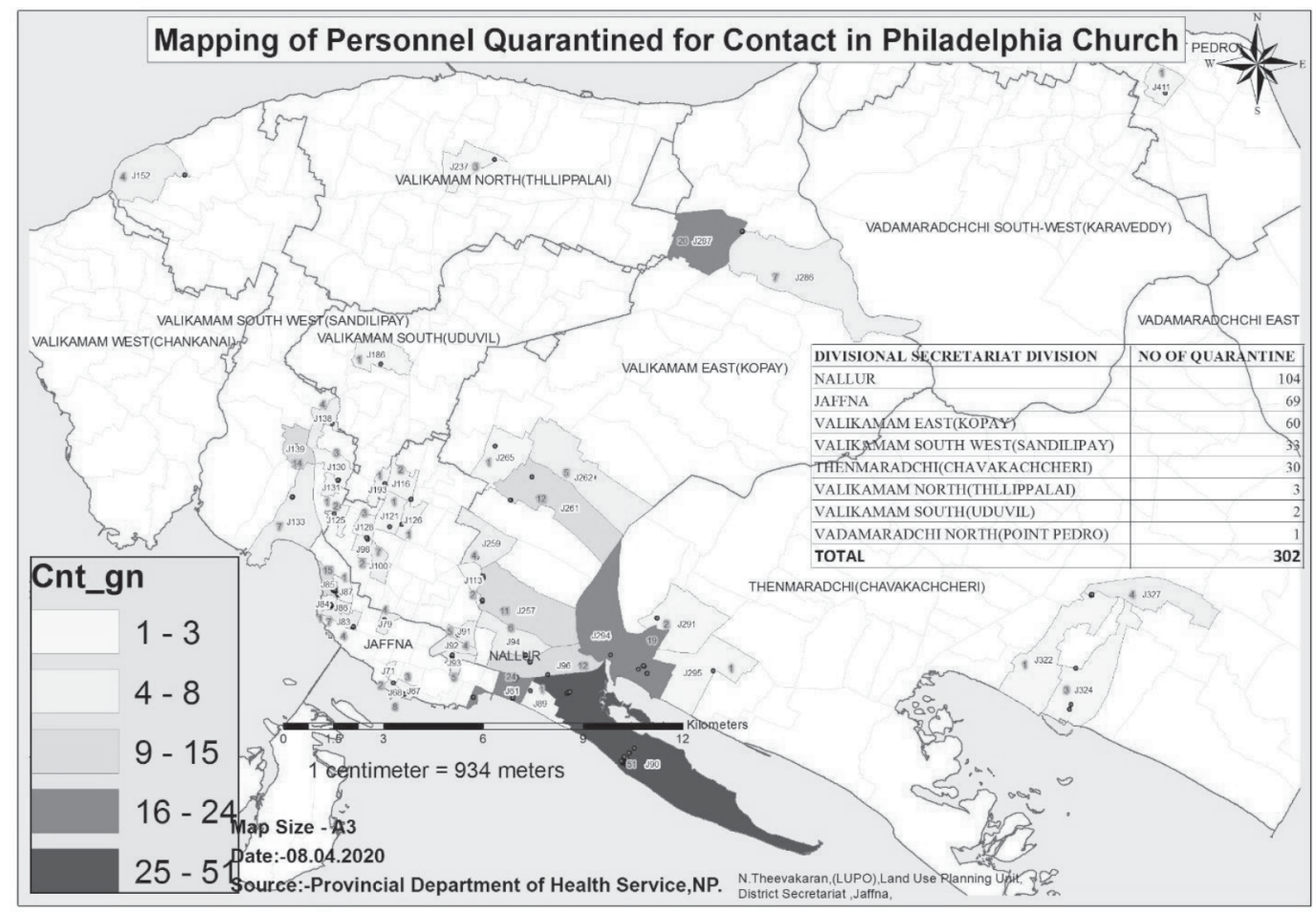

Figure 1: Mapping of personnel quarantined for contact in Philadelphia Church 
- Measures taken after the visit of 'pastor from Switzerland' in Northern Province

Soon after the confirmation that a pastor had held a prayer on 15 March 2020 with 300 individuals and found to be sick during the prayers and had been diagnosed of COVID-19 on his return to Switzerland, the following measures were taken.

A special task force inclusive of the officials led by the Provincial Director of Health Service of Northern Province, Regional Director of Health Services of Jaffna District, consultant community physician, regional epidemiologists, medical officers of health $(\mathrm{MOH})$ and public health inspectors (PHI) was formed to trace and track the participants who attended the function at church. The role played by PHIs in this mission was prominent, while other primary contributors consisted of the police, triforces, the local government and the media. Initially, 14 participants were traced, and eventually 300 participants across five districts. The following strategies related to tele-communication and digital media were adopted to accumulate information of the participants at the early stage of the mission.

- Using social media, lists from voluntary informants and participants of the event were obtained.

- Using digital video clips of the event, missing participants were identified

- Extensive public awareness and announcements across the entire province which drives the public to inform authorities (the majority of the participants)

- A hotline was created and made public to obtain information

Within 36 hours, all the participants were traced across the province and quarantined at their respective residence along with the support of police. Among them, 20 participants who claimed to have been in close contact with the pastor were quarantined at the army camp with the help of the military. Subsequently, among those who were quarantined, 17 people were found to be COVID19 positive Among those who were found to be positive one patient was from a town called Thaavady where the contact tracing became difficult so that Thaavady became the first town to be locked down in Sri Lanka. This prompt and scientific way of approach with multi-sectoral involvement and community participation prevented a community transmission which otherwise would have been the same scenario, where a single "super-spreader" known as "patient 31 " - a member of a fringe church called Shincheonji - is thought to have caused the rapid rise in cases in Seoul, Southern Korea (7). It was expected to have several thousands of patients within a month if not for the prompt containment.

\section{Limited activities during non-curfew hours}

All the markets were closed and small vendors were encouraged at village level to minimize crowding. Physical spacing was made mandatory at public transport, while all public gatherings were prohibited. Medical supplies were supplied to the houses of patients who had their outpatient medical records in hospitals to avoid patients crowding in hospitals and to ease their travel burden.

\section{Testing/ Diagnosing}

The participants who attended the function at church were house quarantined and tested twice to be proved to be negative. All the inbound passengers from other provinces who were from previous locked down areas, abroad or suspected to have had contacts with any COVID-19 patients were carefully screened, quarantined and tested. Further, any suspected personnel arriving through sea were screened and quarantined and tested. Apart from this, all the inbound and outbound transport drivers along with their assistants and similar categories were monitored closely with tests.

\section{Conclusion}

Northern Province continues to fight the battle of COVID-19 effectively, while being guided well by the Ministry of Health. There had been zero cases 
during the past month despite hundreds of suspected cases being tested. Thus, Northern Province is likely to set an example on how an imminent community spread could be prevented by effective intersectoral action of a combined effect of contact tracing, quarantine and testing.

\section{Author Declaration}

Acknowledgements: We acknowledge all our cofrontline workers who were instrumental in containing the COVID-19 in the Northern Province. We appreciate and thank the Director General of Health Services, Dr Anil Jasinghe; Deputy Director General of Health Services, Dr Paba Palihawadana and Dr Susie Perera for their valuable guidance. Regional Director of Health Services Jaffna, Mannar, Mullaithevu, Vavuniya and Kilinochchi along with their Regional Epidemiologists and Public Health Inspectors are acknowledged for their valuable contribution towards the containment

Author contributions: All authors were involved in planning of the article and in literature search. The main author drafted the manuscript and all authors were involved in editing it. All authors approved the final manuscript.

\section{References}

1. WHO. Coronavirus (COVID-19) events as they happen. World Health Organization, 2020
Available from: https://www.who.int /emer gencies/diseases/novel-coronavirus-2019/eventsas-they-happen. Accessed 8 May 2020.

2. Bai Z, Gong Y, Tian X, Cao Y, Liu W, Li J. The rapid assessment and early warning models for COVID-19. Virologica Sinica 2020; 35: 272-279. DOI: 0.1007/s12250-020-00219-0.

3. WHO. Paradox of healthcare in Sri Lanka A snapshot of the last decade from a partnership of sixty years, 2014. Available from: https://apps. who.int/iris/handle/10665/255195.

4. Ediriweera DS, de Silva NR, Malavige NG, de Silva HJ. An epidemiological model to aid decision making for COVID-19 control in Sri Lanka. Available from: http://medrxiv.org/ content/early/2020/04/16/2020.04.11.20061481. Accessed 8 May 2020.

5. WHO. Risk assessment. Available from: https://www.who.int/publications-detail /risk-. Accessed 8 May 2020.

6. WHO. Operational considerations for case management of COVID-19 in health facility and community interim guidance. Available from: https://apps.who.int/iris/handle /10665/331492. Accessed 19 March 2020.

7. Shim E, Tariq A, Choi W, Lee Y, Chowell G. Transmission potential and severity of COVID-19 in South Korea. International Journal of Infectious Diseases 2020; 93: 339-344. DOI: 10.1016/j.ijid.2020.03.031. 